\title{
The challenge of the implementation and evaluation of hospital-based cancer registry in Indonesia's national referral hospital
}

Soehartati Gondhowiardjo, Ericko Ekaputra, Achmad Randi, Vito Filbert Jayalie

pISSN: 0853-1773 - elSSN: 2252-8083 https://doi.org/10.13181/mji.bc.203785 Med J Indones. 2020;29:431-5

Received: May 24, 2019

Accepted: August 06, 2020

Authors' affiliations:

Department of Radiation Oncology, Faculty of Medicine, Universitas Indonesia, Cipto Mangunkusumo Hospital, Jakarta, Indonesia

\section{Corresponding author:}

Soehartati Gondhowiardjo

Department of Radiation Oncology, Cipto

Mangunkusumo Hospital, Jalan Pangeran

Diponegoro No. 71, Kenari, Senen,

Central Jakarta 10430, DKI Jakarta,

Indonesia

Tel/Fax: +62-21-3921155

E-mail: gondhow@gmail.com

\begin{abstract}
BACKGROUND To lower the burden caused by cancer, the Ministry of Health of the republic of Indonesia requires valid data collection to plan and evaluate cancer programs. This study aimed to evaluate the challenge of developing a cancer registry (CanReg) in Cipto Mangunkusumo Hospital.
\end{abstract}

METHODS This was an observational study on the implementation of cancer registration from the initial licensing until the creation of valid and accurate data, also the challenges in implementing hospital-based cancer registry (HBCR) in Cipto Mangunkusumo Hospital.

RESULTS Cancer registry was developed in 2016 using the 2013 Indonesian version of CanReg5 program called SriKandl. We identified some problems in this registry implementation, such as legal and human resources, medical records, electronic health records, and the CanReg5 program. Moreover, this team processed 886,086 raw patients' data with fairly good topography and age data completeness.

CONCLUSIONS Several obstacles were encountered upon the establishment of HBCR at Cipto Mangunkusumo Hospital from program to bureaucracy and resources. Nevertheless, CanReg data can be used as a basis for decision making by stakeholders.

KEYWORDS cancer, hospitals, registries
Cancer is currently a disease that occupies the top three ranks of the highest number of diseases worldwide (incidence/prevalence). In developed countries such as the United States, cancer incidence in 2012 reached 442.88 cases per 100,000 individuals in a year where prostate cancer ranked first, followed by breast cancer, lung cancer, melanoma, and colorectal cancer. ${ }^{1}$ Unlike in India, which is a developing country, breast cancer is the most common cancer in the country followed by cervical, lips and oral cavity, and colorectal cancer; however, only 94 cases/100,000 individuals/year are reported in India. ${ }^{2}$ In Malaysia, which is the closest country to Indonesia, the most common cancers are lung, colorectal, and prostate cancer. ${ }^{3}$ Based on the previous data, cancer is a major health problem in both developed and developing countries, and different patterns of cancer incidence exist for each country. A good cancer registration system is crucial so that relevant data can be used for policymaking.

The global burden of cancer estimated that cancer incidence in Indonesia has reached 134 cases per 100,000 individuals. Basic health research (RISKESDAS) in 2013 found that the cancer incidence in Indonesia was 1.4 per 1,000.4-6 Currently, the multinational contribution data for cancer estimation in Indonesia were extrapolated by other nations with good cancer registration system..$^{7-10}$ With the high morbidity and cost burden caused by cancer, the Ministry of Health of the republic of Indonesia 
needs the most current and robust data to establish strategic policies that prevent increasing morbidity and cost burden caused by cancer. ${ }^{11-13}$

With the availability of cancer profile data, health development priorities such as the provision of labor, infrastructure, and tools can be adjusted depending on the cancer profile obtained. Similarly, in a small scope at Cipto Mangunkusumo Hospital, cancer profiles were found to be crucial to create policies in the fields of providing labor, developing rooms and equipment, and purchasing drugs. Thus, the board of directors must prioritize the allocation of appropriate budget funds to achieve such policies. ${ }^{13,14}$ According to the Indonesian Ministry of Health Order No. 1068/ Menkes/SK/XI/2008, the National Cancer Registry was established, with the pilot project conducted in DKI Jakarta Province. The outcome data would contribute to the Cancer Incidence in Five Continents Vol. $X$ release by International Agency for Research on Cancer (IARC), but the data were rejected because of their poor quality. Hospital-based cancer registry (HBCR) in Cipto Mangunkusumo Hospital was initiated on April 2016 to improve the data quality. A joint decree about the establishment of the oncology center was officially signed by the Director of Cipto Mangunkusumo Hospital and the Dean of the Faculty of Medicine Universitas Indonesia. The cancer registration unit, where this study based, was coordinated by the oncology center of Cipto Mangunkusumo Hospital. ${ }^{15}$ Thus, this study aimed to evaluate the challenges of cancer registry development in a hospital setting.

\section{METHODS}

This work was an observational study on the implementation of cancer registration from the initial licensing until the creation of valid and accurate data, as well as a discussion on the challenges in implementing $\mathrm{HBCR}$ in Cipto Mangunkusumo Hospital. This study was conducted in 2016, in accordance with the establishment of

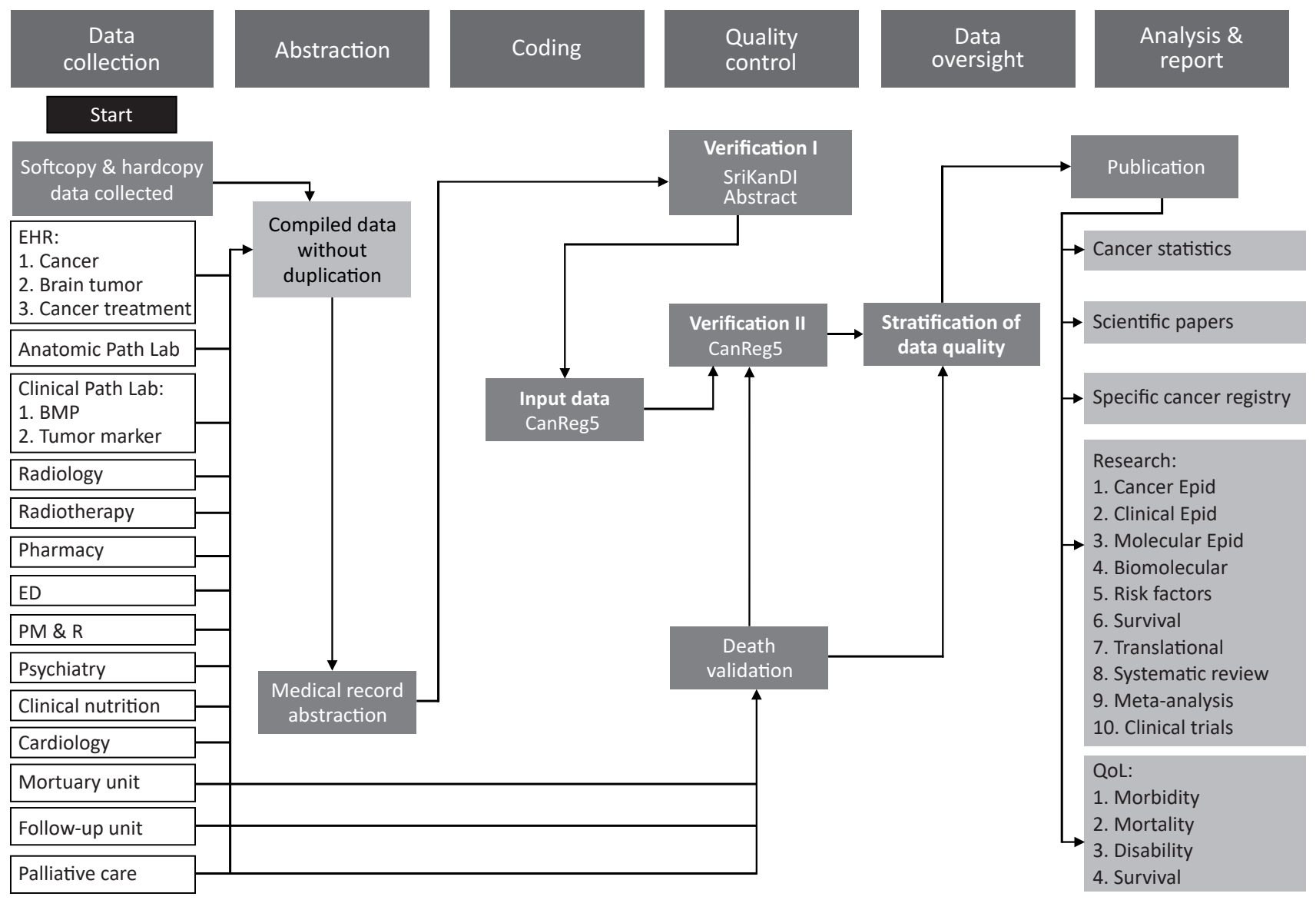

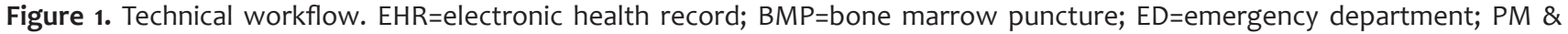
$\mathrm{R}=$ physical medicine and rehabilitation; CanReg=cancer registry; QoL=quality of life 
our cancer registry. The data provided by HBCRCipto Mangunkusumo Hospital comprised the population based cancer registry in DKI Jakarta and Indonesia. All sections related to the formation of cancer registration in Cipto Mangunkusumo Hospital will be part of the study. The subjects in this study were all cancer-diagnosed medical records from any department in Cipto Mangunkusumo Hospital, from January to December 31, 2013. Patients who were followed up completely before the definite diagnosis was made were excluded (follow-up was performed repeatedly until October 2016). Duplicate data were processed by manual filtering through Microsoft Office Excel software (Figure 1).

\section{RESULTS}

\section{Cancer registry}

Raw data were collected since May 1, 2016; nine registrars and an authenticator staff were recruited. Follow-up was carried out by the registrars, and the abstraction began on October 2016. Data abstraction was managed in two stages: initial filter (compile data and eliminate duplicate) and final filter (capture and recapture methods). All verification and entry processes were finished in 1 month since the abstraction began, followed by regular evaluation and monitoring by the National Controller of Cancer Registry. The Cipto Mangunkusumo Hospital Cancer Registry processed 886,086 raw data to 5,554 clean data as the final registry pooled 2013 data (Table 1).

\section{HBCR data quality}

Table 2 shows the analysis of HBCR data quality. Based on the criteria, some data did not meet the IARC "Grade A" standard. Total microscopic verification (MV) and MV without hepatocellular carcinoma was more than $75 \%$ and $80 \%$, respectively. A small percentage of data was classified as unknown primary (0.8\%), death certificate only (2.3\%), and ill-defined site (0.5\%). No incomplete topology and incomplete age were found.

\section{Completeness of HBCR variables}

In the analysis of the completeness of $\mathrm{HBCR}$ variables (Table 3), all sex and age data were found in all medical records of patients with cancer. We found that 500 addresses were missing. The most incomplete entry was cancer stage, and 2,723 (49\%) cases lacked cancer stage information in their records.
Table 1. $H B C R$ data management in Cipto Mangunkusumo Hospital in 2013

\begin{tabular}{|c|c|c|c|c|}
\hline No & Departments/divisions & Raw data & $\begin{array}{l}\text { Initial } \\
\text { filter }\end{array}$ & $\begin{array}{l}\text { Final } \\
\text { filter }\end{array}$ \\
\hline \multirow[t]{4}{*}{1} & EHR & & & \\
\hline & Outpatients & 498,198 & 59,954 & 5,035 \\
\hline & Inpatients & 34,528 & 6,300 & - \\
\hline & Support services & 130,822 & - & - \\
\hline \multirow[t]{2}{*}{2} & Anatomical pathology & & & \\
\hline & $\begin{array}{l}\text { Malignant } \\
\text { neoplasms, stated } \\
\text { or presumed to be } \\
\text { primary; malignant } \\
\text { neoplasms, stated } \\
\text { or presumed to be } \\
\text { secondary; unknown, } \\
\text { CNS, cytology }\end{array}$ & 23,974 & 21,016 & 3,085 \\
\hline 3 & Radiotherapy & 1,646 & - & 1,646 \\
\hline \multirow[t]{3}{*}{4} & Pediatric hematology & & & \\
\hline & BMP & 554 & - & 435 \\
\hline & Pediatric & 2,148 & 1,656 & 283 \\
\hline 5 & Neurosurgery & 732 & 378 & 113 \\
\hline 6 & Urology & 82 & - & 82 \\
\hline 7 & Orthopedic surgery & 92 & - & 92 \\
\hline 8 & Dermatovenerology & 107 & - & 52 \\
\hline 9 & Ophthalmology & 157 & - & 157 \\
\hline 10 & Gynecologic oncology & 2,766 & 857 & 845 \\
\hline \multirow[t]{3}{*}{11} & Radiology (2013-2014) & & & \\
\hline & CT scan & 11,902 & - & 1,442 \\
\hline & MRI & 103 & - & - \\
\hline 12 & ENT & 4,927 & - & 780 \\
\hline 13 & Neuro-oncology & 870 & - & 870 \\
\hline 14 & BPJS/Jamkes 2013 & 24,091 & - & - \\
\hline 15 & BPJS 2014 & 147,743 & - & - \\
\hline \multirow[t]{2}{*}{16} & Death certificate & 644 & - & 525 \\
\hline & Total & 886,086 & 90,161 & 15,442 \\
\hline
\end{tabular}

$\mathrm{HBCR}=$ hospital-based cancer registry; EHR=electronic health record; $\mathrm{CNS}=$ central nervous system; $\mathrm{BMP}=$ bone marrow puncture; $\mathrm{CT}=$ computed tomography; $\mathrm{MRI}=$ magnetic resonance imaging; ENT=ear nose throat; BPJS=Badan Penyelenggaraan Jaminan Sosial (Indonesian Health Insurance Service); Jamkes=Jaminan Kesehatan (Indonesian Insurance Service for the poor and near-poor)

\section{Legal basis}

The Cipto Mangunkusumo Hospital Cancer Registration Unit is operating structurally under the Cipto Mangunkusumo Hospital Oncology Center. This is in line with Minister of Health Decree No. HK 02.02/ MENKES/410/2016 concerning the Implementing Hospital for Cancer Registration and Data Control 
Table 2. Data quality of hospital-based cancer registry in Cipto Mangunkusumo Hospital 2013

\begin{tabular}{lccc}
\hline No & IARC parameters & Cut-off (\%) & $\%(\mathrm{~N}=5,554)$ \\
\hline 1 & Unknown primary (C80.9) & $<10$ & 0.8 \\
2 & DCO & $<10$ & 2.3 \\
3 & III-defined site (C76) & $<10$ & 0.5 \\
4 & Total MV & $>75$ & 73 \\
\hline 5 & MV without HCC & $>80$ & 74.5 \\
6 & Uncompleted topology & $<10$ & 0 \\
7 & Uncompleted age & $<10$ & 0 \\
\hline
\end{tabular}

IARC=International Agency for Research on Cancer; DCO=death certificate only; $\mathrm{MV}=$ =microscopic verification; $\mathrm{HCC}=$ hepatocellular carcinoma

Table 3. Analysis of the completeness of 2013 Cipto Mangunkusumo Hospital HBCR variables

\begin{tabular}{lcc}
\hline \multirow{2}{*}{ Variable } & \multicolumn{2}{c}{ Data availability, $\mathrm{n}(\%)$} \\
\cline { 2 - 3 } & \multicolumn{1}{c}{ Available } & Missing \\
\hline Gender & $5,554(100.0)$ & $0(0)$ \\
Age & $5,554(100.0)$ & $0(0)$ \\
Patient's address & $5,054(91.0)$ & $500(9.0)$ \\
Topography & $5,554(100.0)$ & $0(0)$ \\
Morphology & $4,759(85.7)$ & $795(14.3)$ \\
Stage & $2,831(51.0)$ & $2,723(49.0)$ \\
Basic diagnosis & $5,543(99.8)$ & $11(0.2)$ \\
\hline
\end{tabular}

$\mathrm{HBCR}=$ hospital-based cancer registry

Center Hospital for National Cancer Burden. ${ }^{16}$ The establishment of the oncology center was officially executed after a joint decree was signed between the Director of the Cipto Mangunkusumo Hospital and the Dean of the Faculty of Medicine Universitas Indonesia with the letter-number HK.02.05/XI.3/11062/2016 on April 27, 2016. One of the tasks of the oncology center based on the decree was to establish a comprehensive and continuous cancer registration system at Cipto Mangunkusumo Hospital. The Cipto Mangunkusumo Hospital cancer registration unit was formed based on the legal provisions.

\section{Human resources}

Registrars and verifiers were recruited in April 2016. Nine registrars and one verifier were recruited with Bachelor of Public Health and General Practitioner qualifications on May 1, 2016. Initial cancer registration training was carried out for the ten staff members at Dharmais Cancer Hospital on May 9-14, 2016. Further training was also conducted afterward.

\section{DISCUSSION}

The development of cancer registration faces many obstacles in the early phases. The cancer registration decision letter is still integrated with the one from the oncology center. In the future, especially when Cipto Mangunkusumo Hospital has been established as the national referral hospital for cancer registration implementation, a separate decree will help the legal basis in implementing cancer registration.

Some obstacles in Cipto Mangunkusumo Hospital's central medical record unit were inaccuracy of medical status received compared with the list of medical status ordered by the cancer registration team. Examination of the medical status received daily revealed that $40 \%$ of cases were not cancer cases. Consequently, the abstraction was not completed on time. The medical status for some patients varied. These patients had the same medical record number, so the patients were called twice.

The incompleteness of medical status was a significant hindrance for the registrar to complete the abstraction. Based on the recapitulation, $63 \%$ of the status had no national identity number of the patient written on it, the examination report was not attached, and the same medical record number was shared for different patients. The patient's name written with only one word made duplication difficult to recognize. The written medical status was often unreadable because of the poor handwriting of the medical staff. The staging was often left blank, making abstraction difficult because of many missing points.

In the electronic medical record/electronic health record (EHR), a large body of data had the International Classification of Diseases 10th Revision code for different cancers $(>3)$ on a single medical record number, implying that the patient was diagnosed with more than three different types of cancer. Our observations on Cipto Mangunkusumo Hospital's central medical record unit strongly indicated a need for coding training and clarification for the diagnosis and staging on a patient's medical status.

Patients' medical records will be discarded after 5 years per hospital regulation; thus, some patient records were not found. Although we searched through the internal medical records of every basic 
data from related departments, some data were still lacking. Some departments also did not provide the full data as mentioned on the cancer registry form. Furthermore, human-related errors may occur in filtering the data due to the immense amount of data collected and manual duplicates.

From a legal aspect, we believe a separate decree is necessary as the legal basis for the implementation of a cancer registry. We recommend the implementation of an integrated EHR in the cancer registry system to simplify the diagnosis coding system and for statistical purposes. Adequate financial support and number of staff are also essential. We suggest further training in diagnosis coding and staging to the staff. If cancer registry (CanReg5) would be used, we agree with a previous publication by Godjali et al, ${ }^{17}$ who suggested that CanReg5 must be fixed and improved. Given that this program can benefit patients, physicians, and stakeholders, we recommend the implementation of this registry system to other hospitals. Skillful human resources, legal basis, and financial support from each hospital are also essential to support the implementation and evaluation of this cancer registry system.

In conclusion, several obstacles were encountered upon the establishment of HBCR at Cipto Mangunkusumo Hospital. These problems included the bureaucracy, legal and human resources, administration, medical record status, EHR, and the CanReg5 program itself. Nevertheless, the cancer registry team processed 886,086 raw data to 5,554 clean cancer in 2013. This paper also provides insight into HBCR data in Cipto Mangunkusumo Hospital. Cancer registration data generated from this study can be used as a basis for decision making by stakeholders.

Conflict of Interest

The authors affirm no conflict of interest in this study.

Acknowledgment

None.

\section{Funding Sources}

None.

\section{REFERENCES}

1. National Cancer Institute. SEER cancer statistics review, 19752012. SEER Cancer Stat Rev 1975-2012 [Internet]. National Cancer
Institute: U.S. Department of Health and Human Services; 2015 [cited 2018 Dec 29]. Available from: http://seer.cancer.gov/ csr/1975_2012/.

2. Vijayakumar M, Ramesh C, Ramachandra Reddy K. Leading sites of cancer in India. Consol Rep HBCR, 2007-2011. 2010;1:1-16.

3. Globocan. Fact sheets by population [Internet]. 2014 [cited 2019 Jan 20]. Available from: http://globocan.iarc.fr/Pages/fact_ sheets_population.aspx.

4. Bray F, Jemal A, Grey N, Ferlay J, Forman D. Global cancer transitions according to the Human Development Index (20082030): a population-based study. Lancet Oncol. 2012;13(8):790801.

5. Torre LA, Bray F, Siegel RL, Ferlay J, Lortet-Tieulent J, Jemal A. Global cancer statistics, 2012. CA Cancer J Clin. 2015;65(2):87108.

6. Ministry of Health of the Republic of Indonesia. Health minister announced a commitment to tackling cancer in Indonesia. [Internet]. Jakarta: Ministry of Health of the Republic of Indonesia; 2015 [cited 2019 Jan 20]. Available from: http://www. depkes.go.id/article/view/15020400003/menkescanangkankomitmen-penanggulangan-kanker-di-indonesia.html. Indonesian.

7. Sohier BR, Sutherland $A G B$. The International Agency for Research on Cancer [Internet]. 2015 [cited 2019 Jan 19]. Available from: http://www.iarc.fr/.

8. Chiang CJ, You SL, Chen CJ, Yang YW, Lo WC, Lai MS. Quality assessment and improvement of nationwide cancer registration system in Taiwan: a review. Jpn J Clin Oncol. 2015;45(3):291-6.

9. Larsen IK, Småstuen M, Johannesen TB, Langmark F, Parkin DM, Bray F, et al. Data quality at the Cancer Registry of Norway: an overview of comparability, completeness, validity and timeliness. Eur J Cancer. 2009;45(7):1218-31.

10. Parkin DM, Bray F. Evaluation of data quality in the cancer registry: principles and methods Part II. Completeness. Eur J Cancer. 2009;45(5):756-64.

11. Siesling S, Louwman WJ, Kwast A, van den Hurk C, O'Callaghan $M$, Rosso S, et al. Uses of cancer registries for public health and clinical research in Europe: results of the European Network of Cancer Registries survey among 161 population-based cancer registries during 2010-2012. Eur J Cancer. 2015;51(9):1039-49.

12. Anttila $A$, Lönnberg $S$, Ponti $A$, Suonio E, Villain $P$, Coebergh JW, et al. Towards better implementation of cancer screening in Europe through improved monitoring and evaluation and greater engagement of cancer registries. Eur J Cancer. 2015;51(2):241-51.

13. Ruiz A, Facio Á. Hospital-based cancer registry: a tool for patient care, management and quality. A focus on its use for quality assessment. Rev Oncol. 2004;6(2):104-13.

14. The ACTION Study Group. Catastrophic health expenditure and 12-month mortality associated with cancer in Southeast Asia: Results from a longitudinal study in eight countries. BMC Med. 2015;13(1):190.

15. Indonesia Ministerial of Health Decree. Guideline on classification and standard of teaching hospital. 2008 [cited 2020 Jul 12]. Available from: http://bprs.kemkes.go.id/v1/ uploads/pdffiles/peraturan $/ 5 \% 20$ KMK\%20No. $\% 201069 \% 20 t$ tg $\% 20$ Pedoman\%20Klasifikasi\%2odan\%20Standar\%20RS\%20Pendidikan. pdf. Indonesian.

16. Indonesia Ministerial of Health Decree. Cancer registration managing hospital and national cancer burden data control center. 2016 [cited $2020 \mathrm{Jul}$ 12]. Available from: https://www. persi.or.id/images/regulasi/kepmenkes/kmk4102016.pdf. Indonesian.

17. Godjali DD, Pardamean B, Suzanna E. Development of Indonesia's cancer registration system. Indonesian Journal of Cancer. 2012;6(2):61-6. Indonesian. 